\title{
Pemikiran Pendidikan dan Perjuangan Raden Ayu Kartini Untuk Perempuan Indonesia
}

\author{
Karlina, Hudaidah \\ Universitas Sriwijaya \\ linak3456@gmail.com \\ hudaidah@fkip.unsri.ac.id
}

\begin{abstract}
Abstrak
Raden Ajeng Kartini atau biasa disebut Raden Ayu (R.A.) Kartini adalah seorang tokoh Jawa dan Pahlawan Nasional Indonesia dan beliau juga dikenal sebagai Pelopor Kebangkitan Perempuan Pribumi. Beliau lahir di Jepara, Jawa Tengah 21 April 1879 dan meninggal di Rembang, Jawa tengah 17 September 1904. Tujuan Penelitian ini adalah untuk mengetahui Pemikiran dan perjuangan R.A. Kartini tentang pendidikan perempuan pribumi, karena untuk menjadi perempuan yang berpendidikan sebelum tahun 1900-an adalah hal yang sangat sulit dicapai oleh kaum perempuan. Perempuan tidak diperbolehkan untuk mendapatkan pendidikan, berawal dari masalah tersebut timbulah pemikiran-pemikiran R.A. Kartini. Dalam penelitian ini menggunakan metode penelitian kepustakaan. Berdasarkan hasil penelitian dapat disimpulkan bahwa R.A. Kartini memandang bahwa Pendidikan adalah suatu hal yang sangat penting, dengan pendidikan mampu mengangkat derajat dan mampu mengangkat martabat bangsa Indonesia baik itu pendidikan untuk laki-laki maupun untuk perempuan dan cita-cita yang diinginkan R.A. Kartini adalah membangun sekolah wanita.
\end{abstract}

Kata Kunci: Pemikiran; Pendidikan; Kartini; Perempuan

\begin{abstract}
Raden Ajeng Kartini or so-called Raden Ayu Kartini is a Javanese figure and Indonesian National Hero and he is also known as a pioneer of the rise of Indigenous women. He was born in Jepara, Central Java 21 April 1879 and died in Rembang, Central Java 17 September 1904. The purpose of this study was to determine the thoughts and struggles of R.A Kartini on the education of indigenous women, because to become educated women before the 1900s was very difficult for women to achieve. Because women were not allowed to get education, starting from this problem the thoughts of R.A Kartini arose. In this study, using the library research method. Based on the results of the research it can be concluded that R.A Kartini views that education is a very important thing, with education being able to elevate the degree and being able to elevate the dignity of the Indonesian nation both education for men and for women. And the dream that R.A Kartini wants is to build a women's school.
\end{abstract}

Keyword: Thought; Education; Kartini; Women 


\section{Pendahuluan}

Pada hakikatnya pendidikan adalah sesuatu yang dibutuhkan untuk membangun peradaban bangsa melalui membangun manusia. Pendidikan adalah hak setiap manusia yang berfungsi untuk meningkatkan harkat dan martabat. Seiring perkembangan zaman, pendidikan berkembang secara dinamis. Aspek pendidikan merupakan suatu hal yang tidak dapat dipisahkan dari kelangsungan hidup bangsa Indonesia. Dengan pengaruh masuknya Islam ke indonesia juga merubah pola dan sistem pendidikan yang sudah lama berjalan di Hindia-Belanda.Pendidikan pada masa Hindu-Budha yang ditujukan bagi kalangan bangsawan. Pola pendidikan mulai berubah ketika memasuki awal abad ke-20, karena pada masa ini pendidikan sudah mulai memiliki tujuan lain. Pemerintah kolonial Belanda yang mulai mengembangkan industrialisasi sangat banyak membutuhkan tenaga kerja yang terdidik. Selanjtnya pada permulaan abad ke-20 mulai muncul sebuah kesadaran mengenai nasionalisme. Pada masa ini, mulai bangkit kesadaran masyarakat Indonesia karena itu disebut masa kebangkitan nasional. Kesadaran nasional mulai tumbuh bermula dari kebijakan pemerintah Kolonial Belanda yang biasa dikenal dengan politik ethis (Rifa'i, 2011: 59)

Ketika berbicara mengenai kaum perempuan memang sangat menarik dan tidak ada habisnya, karena kaum perempuan mungkin tidak bisa menduduki posisi sebagai "high profile", tetapi terkait dengan segala isu yang menyangkut perempuan seperti kedudukan, peranan, dan kesetaraannya dengan laki-laki masih menjadi isu yang sangatkontroversial. Sebelum perkembangan abad ke-20 kaum perempuan tidak bisa atau tidak boleh disejajarkan dengan kaum laki-laki dalam hal apapun, khususnya dalam hal pendidikan. Perempuan tidak diperbolehkan untuk memperoleh hak pendidikan dan melakukan interaksi sosial (Menteri Negara Pemberdayaan Perempuan Republik Indonesia, 2000: v)

Perempuan hanya bertugas di rumah, sebagai istri yang baik dan sebagai ibu yang baik tanpa adanya kebebasan apapun bahkan perempuan pun tidak memperoleh kebebasan dalam berfikir atau menuangkan pemikirannya. Dengan melihat isu atau permasalahan di atas, maka tergugahlah hati beberapa tokoh perempuan salah satunya adalah Raden Ajeng Kartini untuk mengubah pola pikir masyarakat tentang perempuan, dan mengubah kedudukannya sejajar dengan laki- 
laki, terlebih dalam hal perjuangan dan pemikiran R.A. Kartini tentang pendidikan perempuan di Indonesia. Kemudian persamaan derajat yang digagas oleh R.A. Kartini adalah sebuah bentuk emansipasi wanita. Salah satunya bidang pendidikan, dimana perempuan juga seharusnya mendapatkan haknya untuk memperoleh pendidikan, hak dalam menuangkan pemikirannya, dan haknya dalam berinteraksi atau bersosialisasi dengan masyarakat, karena sejatinya manusia adalah makhluk social yang harus saling berinteraksi kepada sesame masyarakat. Cita-cita yang diinginkan R.A. Kartini adalah membangun Sekolah wanita agar wanita mendapatkan pendidikan dengan baik dan layak (Nata, 1997: 9-10)

R.A. Kartini adalah salah satu tokoh yang berbeda dari beberapa tokoh lainnya, karena dengan keberhasilan dan kegigihannya atau semangat perjuangan emansipasinya dijadikan sebagai bentuk kepahlawanan. Kemudian beliau dikukuhkan sebagai pahlawan Republik Indonesia yang tertera dalam Surat Keputusan Presiden RI Nomor 108 pada tanggal 02 Mei 1964. Sekarang setiap tanggal 21 April atau tanggal kelahirannya diperingati sebagai Hari Kartini. Diberikannya gelar tersebut menuai banyak kritik di kalangan masyarakat. Perjuangan Kartini dianggap hanya sebatas perjuangan lokal masyarakat Jawa khususnya Kabupaten Jepara. Namun, Saat ini peran perempuan Indonesia menjadi sangat kompleks, baik dalam kesetaraan pendidikan, ekonomi, budaya, politik, maupun lainnya (Mu'thi, 2002: 54).

Berdasarkan dari latar belakang atas permasalahan di atas, maka penelitian ini bertujuan untuk mendeskripsikan pemikiran dan perjuangan Raden Ajeng Kartini tentang pendidikan Perempuan Indonesia dan menganalisis pemikiran pendidikan perempuan Raden Ajeng Kartini. Oleh karena itu urgensi penelitian ini penting memberikan kontribusi bagi pemikiran pendidikan perempuan di Indonesia yang dilandasi oleh semangat R.A. Kartini dan kepentingan bangsa untuk membuat kaum perempuan maju dan setara dengan laki-laki dalam pendidikan.

\section{Metode Penelitian}

Metode penelitian yang digunakan adalah metode penelitian kepustakaan, penelitian ini membahas teori-teori yang dikaji secara ulang. Selain itu penelitian ini juga menggunakan paradigma kualitatif yang bersifat deskriptif. Pemikiran 
pendidikan Kartini dijelaskan secara deskriptif, yaitu dengan mengungkapkan dan menjelaskan peristiwa penting yang telah terjadi. Pendekatan yang digunakan adalah pendekatan historis dan biografi yang artinya menceritakan kembali suatu sejarah dan peristiwa penting yang lebih menekankan pada kronologi cerita. Penelitian ini menggunakan telaah dokumen sebagai metode pengumpulan datanya, yaitu mencari hal-hal mengenai pemikiran Kartini baik berupa surat kabar, transkip, catatan dan lainnya. Sumber data peneliti menggunakan literatur kepustakaan yang mengkaji tentang pemikiran Kartini. Analisisnya menggunakan teknik penelitian yang dimanfaatkan untuk menarik kesimpulan dari data yang telah diperoleh (Moleong, 2004: 10).

\section{Pembahasan}

Pendidikan merupakan sesuatu hal yang bisa dikatakan sangat penting, dengan pendidikan mampu mengangkat derajat dan mampu mengangkat martabat bangsa Indonesia dan pendidikan juga tidak terbatas pada jenis kelamin, baik laki laki maupun perempuan berhak memperoleh pendidikan. Suatu bangsa tidak akan maju apabila kaum perempuannya tidak berpendidikan. Perempuan bukanlah sosok yang akan menjadi saingan bagi kaum laki-laki tetapi mereka adalah pendukung yang akan bekerja sama dalam membangun sebuah bangsa yang besar. Menurut R.A. Kartini dengan adanya pendidikan maka kita dapat membuat peradaban bangsa Indonesia lebih maju. Oleh karena itu, telah banyak ia sampaikan kepada sahabatsahabat penanya mengenai pemikiran pendidikan perempuan di Indonesia melalui surat-suratnya.

Pendapat R.A. Kartini mengenai kaum perempuan mempunyai andil besar dalam memajukan peradaban bangsa bukan hanya sekedar angan-angan kecil namun sebuah cita-cita besar R.A. Kartini, sebab pendapat tersebut telah beliau sampaikan kepada semua sahabat- sahabat penanya (Rifa'i, 2011: 59) antara lain sebagai berikut:

1. Kartini menyampaikan kepada Nyonya Van Kol. Bahwa pendidikan yang akan diberikan kepada kaum perempuan akan menjadikan bangsa Indonesia menjadi bangsa yang maju dan bangsa yang lebih beradab. Menurut beliau, perempuan yang telah berpendidikan akan mampu ikut serta dalam membangun dan 
mengubah bangsa Indonesia menjadi bangsa yang maju. Beliau percaya bahwa kaum perempuan mampu bekerjasama dan berdampingan dengan kaum laki-laki.

2. Kartini menyampaikan kepada Tuan dan Nyonya Anton. Apabila kaum perempuan yang telah berpendidikan diikutsertakan dalam melaksanakan pekerjaan, maka beliau percaya kaum perempuan dapat memajukan peradaban bangsa Indonesia dan akan semakin cepat kemajuan bangsa Indonesia.

3. Kartini menyampaikan kepada Nyonya Abendanon. Pada tanggal 21 Januari tahun 1901, R.A. Kartini menyampaikan surat yaitu: Perempuan sebagai pendukung peradaban! Bahkan tidak hanya perempuan yang akan dianggap pandai dan cakap, tetapi saya yakin dengan sangat bahwa perempuan dapat membawa pengaruh besar atau dampak positif untuk bangsa Indonesia, negative atau positifnya tetap akan memberikan akibat besar bagi kehidupan: Dan dialah yang akan merubah kehidupan dan martabat manusia (R.A. Kartini, 2017: 112).

Dari isi surat di atas dapat diketahui bahwa kaum perempuan mempunyai potensi besar dalam pengaruhnya terhadap kehidupan. Perempuan bukan hanya seorang ibu, tetapi mereka adalah sosok pembawa peradaban dunia. Di dalam suratnya, R.A. Kartini sangat yakin dan sangat tertarik dengan gerakan yang ada di luar Indonesia, yaitu Eropa. Hal ini pula yang menggerakkan hatinya untuk berjuang demi kesetaraan kaum perempuan. R.A. Kartini merasa sangat prihatin dengan kaumnya yang masih tertindas dan harus selalu tunduk terhadap lakilaki. Menurut beliau bangsa Indonesia tidak akan mempunyai kemajuan apabila masih ada perbedaan derajat antara kaum perempuan dan kaum laki-laki. Laki-laki dan perempuan harus berdampingan dan bersama-sama agar tercapainya kemajuan bangsa Indonesia (Stuers, 2017: 43).

\section{Peran Kartini Untuk Pendidikan}

Peran R.A Kartini dalam memajukan pendidikan di Indonesia adalah salah satu bukti kepeduliannya dan salah satu contoh kontribusi wanita yang dicetak dengan tinta emas dalam sejarah. Karena perempuan tidak diperbolehkan untuk mendapatkan pendidikan, dan perempuan hanya boleh menjadi ibu rumah tangga. berawal dari masalah tersebut timbulah pemikiran-pemikiran R.A. Kartini 
dan beliau mendobrak kondisi yang sangat memprihatinkan tersebut dengan mendirikan sekolah khusus wanita dan beliau juga membangun perpustakaan bagi anak-anak perempuan.

\section{Konsep Pendidikan R. A. Kartini}

Menurut Kartini pendidikan merupakan salah satu alat yang digunakan untuk membuka pikiran masyarakat ke arah modern. Pendidikan merupakan suatu langkah menuju peradaban yang maju, dimana laki-laki dan perempuan saling bekerjasama untuk membangun sebuah bangsa. Persamaan pendidikan adalah salah satu bentuk kebebasan kepada kaum perempuan. kebebasan untuk berdiri sendiri, dan menjadi perempuan yang mandiri, menjadi perempuan yang tidak bergantung pada orang lain atau laki-laki (Pane, 2008: 34).

Tujuan pendidikan perempuan R.A. Kartini adalah menjadikan kaum perempuan sebagai perempuan yang cakap baik serta mandiri yang sadar akan panggilan budinya, sanggup menjalankan kewajibannya dalam masyarakat. Menjadi ibu yang baik, pendidik yang bijaksana, bertanggung jawab, pengatur rumah tangga yang mampu memegang dan mengatur keuangan. Pendidikan pertama seorang anak berasal dari sebuah keluarga terutama adalah seorang ibu. Ibu memiliki peran yang sangat penting dalam memberikan pendidikan kepada anak-anaknya. Seorang ibu yang terdidik akan memberikan pendidikan yang baik kepada anaknya. Dari situlah terbentuk kecerdasan seorang anak (Sutrisno, 2014: 566).

\section{Sekolah Kartini}

Sekolah Kartini pertama kali dibuka oleh R.A. Kartini dan Rukmini pada tahun 1903. Sekolah ini dikhususkan untuk para wanita dan diprakarsai oleh R.A. Kartini pada tahun 1903 di kota Jepara. Pada awal berdiri hanya ada 9 orang dan semakin lama muridnya makin bertambah. Materi yang diajarkan berupa membaca, menulis, menjahit, dan lainnya, seperti konsep pendidikan yang digagas oleh R.A. Kartini tanpa melibatkan kurikulum pemerintah, karena tujuannya bukan hanya memberikan pendidikan umum saja, tetapi juga pendidikan budi pekerti. Sekolah R.A. Kartini juga dibuka di Rembang. Sekolah Kartini juga mengajarkan materi agama, karena agama adalah materi dasar yang dijadikan untuk memahami ilmu 
pengetahuan yang lain. Alasan Kartini mengajarkan materi agama ialah karena agama mempunyai peran yang besar bagi peradaban manusia. Dasar dari pendidikan seorang anak adalah agama yang baik (Mulyohardjo, 2012: 284).

Pada tahun 1904-1914 banyak perubahan salah satunya ialah peraturan kolonial berubah seiring dengan munculnya Politik Etis. Edukasi merupakan suatu hal yang dapat dikatakan memberikan pengaruh besar dan dampak positif meskipun sebelumnya pemberian pendidikan hanya diberikan kepada golongan priyayi dan secara tidak langsung memberi keuntungan kepada pihak kolonial. Salah satu pengaruh atau dampaknya ialah mulai terbukanya jalan untuk pemikiran R.A Kartini. Kartini untuk memberikan pendidikan kepada rakyat, khususnya bagi kaum perempuan. Setelah R.A Kartini menikah, akhirnya sekolah Kartini harus dibubarkan karena kekurangan dana finansial. Namun, pada saat R.A. Kartini wafat yaitu pada tahun 1904 diadakan sebuah kegiatan yaitu pengumpulan dana yang nantinya akan digunakan untuk membangun sekolah Kartini. Pada tahun 1913 didirikanlah sekolah Kartini pertama di Semarang dan Jakarta, kemudian disusul sekolah Kartini di beberapa daerah lainnya. Namun, sampai sekarang masih ada sekolah Kartini, yaitu sekolah yang pertama kali berada di Semarang (Eryudhawan, 2015: 2).

\section{Faktor Pendorong}

Faktor pendorong R.A. Kartini berawal dari masalah tersebut kemudian munculah seorang Kartini yang memperjuangan hak kaum wanita agar tidak ketinggalan zaman dan dapat berfikiran maju seperti wanita di Eropa yang dapat berfikir lebih maju dan modern dan yang paling penting adalah bisa mengenyam pendidikan yang sesuai. Pada saat kejadian masa itu, terjadi suatu masalah yang sangat signifikan yaitu adanya ketidakadilan yang terjadi pada kaum perempuan, dan masalah itu adalah ketidaksetaraan gender antara perempuan dan laki-laki dalam hal seperti aspek pendidikan, sosial, budaya dan lainnya. Dari situlah sebuah faktor pendorong Kartini ingin mendobrak dan menjunjung tinggi martabat seorang kaum perempuan. Namun, R.A Kartini menyadari bahwa untuk membuat bangsanya untuk maju, khususnya pada kaum wanita, maka beliau belajar dengan jalan belajar dari dunia Barat. Peradaban bangsa Barat yang sangat bagus 
membuat R.A Kartini lebih semangat untuk belajar demi membebaskan kaumnya dari ketidakadilan dan ketidaksetaraan itu (Kartini , 2017: 51)

Faktor yang mendorong Kartini ingin memperjuangkan hak seorang perempuan adalah membebaskan kaum perempuan dari kebutaan pendidikan dan pengetahuan dengan mendirikan sekolah khusus, agar hak perempuan untuk mengikuti pendidikan setara. Karena para wanita pada zaman itu tidak mendapatkan pendidikan yang layak sehingga wanita tidak berfikiran maju dan hanya mengandalkan sebuah adat istiadat yang di anut oleh para kaum pribumi. R.A. Kartini dijadikan sebagai pahlawan bangsa Indonesia dilatar belakangi oleh factor factor pendorong Kartini yang salah satunya adalah ingin memperjuangkan hakhak wanita seperti pendidikan dan pemikiran-pemikira perjuangan terhadap kaumnya, yaitu kaum wanita.

\section{Kedudukan Perempuan Pada Masa Sebelum dan Sesudah Masa Kartini}

Secara lebih jelas kedudukan perempuan pada masa dan sebelum R.A. Kartini dapat dijabarkan pada masa sebelum dan sesudah masa Kartini. Pada masa sebelum R.A. Kartini tidak bisa bebas duduk di bangku sekolah, bahkan tidak diperbolehkan untuk bersekolah. Adanya perbedaan antara kaum wanita dan kaum laki-laki dengan ketidakadilan gender yang berdampak pada perempuan seolah olah perempuan tidak mempunyai peran penting dan hanya dituntut untuk menjadi ibu rumah tangga saja. Ketika usia 10 atau 12 tahun kaum perempuan sudah dinikahkan. Sesudah masa Kartini Kaum wanita Sudah bebas dan diperbolehkan bersekolah. Adanya kesetaraan antara kaum wanita dan kaum laki-laki. Perempuan tidak dituntut batasan usia untuk menikah.

\section{Kesimpulan}

Pendidikan akan kuasa mengangkat derajat dan martabat bangsa Indonesia dan pendidikan yang beliau maksud merupakan pendidikan yang dapat diterima oleh semua kalangan, baik laki-laki maupun kalangan perempuan. R.A. Kartini bercitacita mendirikan sekolah atau pendidikan yang mengutamakan pendidikan budi pekerti tetapi juga tetap menggunakan unsur pendidikan agama. R.A. Kartini memperjuangkan kaumnya, agar mereka diberi kebebasan, sehingga bisa 
bersekolah, menuntut ilmu, dan melakukan peran-peran sosial yang luas dan tentunya tidak hanya di dalam rumah. Perjuangan itu tidak mudah. R.A Kartini terus berjuang ketika beliau harus berhadapan dengan sekelompok masyarakat yang tentunya sudah memiliki pola pikir bahwa derajat perempuan dan laki-laki itu berbeda. Namun, perjuangan R.A Kartini ternyata berhasil, sekalipun memerlukan waktu lama dan menghadapi banyak sekali tantangan. Terbukti, dari apa yang terlihat sekarang ini, wanita sedemikian bebasnya. Sudah tidak ada beda hak-hak wanita dan laki-laki. Wanita diperbolehkan menjadi RT, RW, lurah, camat, bupati walikota, gubernur, dan lainnya.

\section{Daftar Rujukan}

Anonim. (2018). Politik Etis, Van Deventer Hingga Douwes Dekker. https://histori.id/politik-etis-van-deventer-hingga-douwes-dekker/. Diakses tanggal 23 Desember 2020.

Eryudhawan, Bambang. (2015). 100 Tahun Bangunan SD Kartini Semarang 19152015. Semarang: YAD.

Horton, Rosalind dan Simmons, Sally. (2009). Wanita-wanita Yang Mengubah Dunia (Terjemahan Haris Munandar). Jakarta: Esensi.

Isnaeni, Hendri F. (2013). Habis Gelap Terbitlah Sekolah. https://historia.id/politik/articles/habis-gelap-terbitlah-sekolah-PGgXP. Diakses tanggal 28 Juni 2020.

Kartini, R.A. (2017). Habis Gelap Terbitlah Terang. Yogyakarta: Penerbit Narasi.

Kartodirdjo, Sartono. (1982). Pemikiran dan Perkembangan Historiografi Indonesia. Jakarta: Gramedia.

Khawari, Nurul. (2012). Kartini dan Perempuan Muda Indonesia. http://www.komnasperempuan.go.id/tafsir-perempuan-untuk-kartini/. Diakses 11 Oktoober 2020.

Kuncoro, Hadi dan Sulistianingsih, (2013). Pahlawan Nasional. Yogyakarta: Familia.

LPPI Makasar. (2013). R.A. Kartini Versus Aisyah We Tenriolle. http://www.lppimakassar.com/2013/05/ra-kartini-versus-aisyah-wetenriollle.html. Diakses 11 Oktober 2020.

Meleong, Lexy. (2004). Metode Penelitian Kualitatif. Bandung: Remaja Rosdakarya.

Menteri Negara Pemberdayaan Perempuan Republik Indonesia. (2000). Kata Sambutan dalam Maftuchah Yusuf, Perempuan Agama dan Pembangunan, Wacana Kritis atas Peran dan Kepemimpinan Wanita. Yogyakarta: Lembaga Studi dan Inovasi Pendidikan. 
Mu'thi, Abdul (2002). Mitos-mitos Perempuan Kurang Akal. Yogyakarta: Gama Media.

Mulyohardjo, Redja. (2012). Pengantar Pendidikan Sebuah Pengantar tentang Dasar-dasar Pendidikan Pada Umumnya dan Pendidikan di Indonesia. Jakarta: Raja Grafindo Persada.

Nata, Abuddin. (1997). Filsafat Pendidikan Islam. Jakarta: Logos Wacana ilmu

Pane, Armijin. (2008). Habis Gelap Terbitlah Terang. Jakarta: Balai Pustaka.

Rifa'i, Muhammad. (2011). Sejarah Pendidikan Indonesia: Dari Masa Klasik Hingga Modern. Yogyakarta: Ar Ruzz Media.

Stuers, Cora vreede. (2017). Sejarah Perempuan Indonesia: Gerakn dan Pencapaian. Depok: Komunitas Bambu.

Sutrisno, Sulastin. (2014). Emansipasi: surat-surat kepada bangsanya 1899-1904. Yogyakarta: Jalasutra. 